\title{
Reply to 'Comment on 'Efficacy and toxicity of treatment with the anti-CTLA-4 antibody ipilimumab in patients with metastatic melanoma after prior anti-PD-1 therapy"
}

Samantha Bowyer ${ }^{1,2}$, Prashanth Prithviraj ${ }^{3,4}$, Paul Lorigan ${ }^{5}$, James Larkin ${ }^{6}$, Grant McArthur ${ }^{7}$, Victoria Atkinson ${ }^{8}$, Michael Millward ${ }^{2,9}$, Muoi Khou ${ }^{10}$, Stefan Diem ${ }^{6}$, Sangeetha Ramanujam ${ }^{11}$, Ben Kong ${ }^{10}$, Elizabeth Liniker ${ }^{11}$, Alexander Guminski ${ }^{11}$, Phillip Parente ${ }^{12}$, Miles C Andrews ${ }^{3,4}$, Sagun Parakh ${ }^{3}$, Jonathan Cebon ${ }^{3,4}$, Georgina V Long ${ }^{11,13}$, Matteo S Carlino ${ }^{10,11,13}$ and Oliver Klein ${ }^{\star 3,4}$

${ }^{1}$ Rockingham General Hospital, Perth, Western Australia, Australia; ${ }^{2}$ School of Medicine and Pharmacology, University of Western Australia, Nedlands, Western Australia, Australia; ${ }^{3}$ Department of Medical Oncology, Olivia Newton-John Cancer Centre, Austin Hospital, Melbourne, Victoria, Australia; ${ }^{4}$ Olivia Newton-John Cancer Research Institute, Melbourne, Victoria, Australia; ${ }^{5}$ The Christie NHS Foundation Trust and University of Manchester, Manchester, UK; ${ }^{6}$ Royal Marsden Hospital NHS Foundation Trust, London, UK; ${ }^{7}$ Peter MacCallum Cancer Centre, Melbourne, Victoria, Australia; ${ }^{8}$ Princess Alexandra Hospital, Greenslopes Private Hospital, Brisbane, Queensland, Australia; ${ }^{9}$ Department of Medical Oncology, Sir Charles Gairdner Hospital, Nedlands, Western Australia, Australia; ${ }^{10}$ Westmead Hospital, Sydney, New South Wales, Australia; ${ }^{11}$ Melanoma Institute Australia, Sydney, New South Wales, Australia; ${ }^{12}$ Box Hill Hospital, Melbourne, Victoria, Australia and ${ }^{13}$ University of Sydney, Sydney, New South Wales, Australia

Sir,

We have read with great interest the correspondence from Imafuku et al. The authors provide further evidence that sequential treatment of anti-PD-1 blockade followed by the application of the anti-CTLA-4 antibody ipilimumab is associated with an increased rate of severe immune-related toxicity (Danlos et al, 2015; Khoja et al, 2015; Aya et al, 2016; Bowyer et al, 2016; Furudate et al, 2016). This contrasts with the reverse treatment sequence where no increased frequency of immunerelated adverse events has been observed (Weber et al, 2015; Ribas et al, 2016). The observations of Imafuku et al suggest that the timing between the administration of the last dose of an anti-PD-1 antibody and the first dose of ipilimumab is a critical factor with all patients who experienced high-grade immune-related toxicity, having received their first dose of ipilimumab within 1 month after the last administration of an anti-PD-1 antibody. In our patient cohort, the median time interval between therapies has been 32 days in patients who developed severe autoimmune toxicity vs 46 days in patients without toxicity, a difference that was statistically not significant. It should also be remembered that a high receptor occupancy is achieved after only a single dose of an anti-PD-1 antibody that persists for several months so that the turnover of PD-1 expressing immune cell populations may also be important in determining the immunological outcome next to the half-life of the antibody itself (Brahmer et al, 2010). The sequence in which PD-1 and CTLA-4 molecules are engaged on effector T cells also leads to vastly different gene expression profiles and one may propose to distinct immunological outcomes providing a potential explanation why differences in immune-related toxicity can be observed depending on the treatment sequence of checkpoint regulators (Das et al, 2015).

Imafuku et al did not present any efficacy data, but it should be emphasised that treatment with ipilimumab after anti-PD-1 failure has significant clinical activity with an objective response rate of $10-15 \%$, which is in keeping with the treatment experience of ipilimumab in antiPD-1 therapy naive patients. This has recently been confirmed in a larger data set of patients who received ipilimumab after progression on pembrolizumab in the Keynote-006 clinical trial (Long et al, 2016).

Overall, these data highlight that ipilimumab is a treatment option after progression on anti-PD-1 therapy and patients should be closely monitored for immune-related adverse events, particularly, if anti-CTLA4 therapy is initiated shortly after the last application of an anti-PD-1 agent. An ongoing randomised clinical trial (NCT02731729) will provide prospective data regarding the efficacy and toxicity of single-agent ipilimumab therapy, or combination therapy of ipilimumab and nivolumab in patients who progress on anti-PD-1 therapy.

\section{CONFLICT OF INTEREST}

The authors declare no conflict of interest.

\section{REFERENCES}

Aya F, Gaba L, Victoria I, Fernandez-Martinez A, Tosca M, Prat A, Arance A (2016) Ipilimumab after progression on anti-PD-1 treatment in advanced melanoma. Future Oncol 12(23): 2683-2688.

Bowyer S, Prithviraj P, Lorigan P, Larkin J, McArthur G, Atkinson V, Millward M, Khou M, Diem S, Ramanujam S, Kong B, Liniker E, Guminski A, Parente P, Andrews MC, Parakh S, Cebon J, Long GV, Carlino MS, Klein O (2016) Efficacy and toxicity of treatment with the anti-CTLA-4 antibody ipilimumab in patients with metastatic melanoma after prior anti-PD-1 therapy. Br J Cancer 114(10): 1084-1089.

Brahmer JR, Drake CG, Wollner I, Powderly JD, Picus J, Sharfman WH, Stankevich E, Pons A, Salay TM, McMiller TL, Gilson MM, Wang C, Selby M, Taube JM, Anders R, Chen L, Korman AJ, Pardoll DM, Lowy I, Topalian SI (2010) Phase I study of single-agent anti-programmed death-1 (MDX-1106) in refractory solid tumors: safety, clinical activity, pharmacodynamics, and immunologic correlates. J Clin Oncol 28(19): 3167-3175.

Danlos FX, Pagès C, Roux J, Jebali M, Gornet JM, Bagot M, Lebbe C (2015) Atypical severe immune-related adverse effects resulting from sequenced immunotherapy in melanoma. Melanoma Res 25: 178-179.

Das R, Verma R, Sznol M, Boddupalli CS, Gettinger SN, Kluger H, Callahan M, Wolchok JD, Halaban R, Dhodapkar MV, Dhodapkar KM (2015) Combination therapy with anti-CTLA-4 and anti-PD-1 leads to distinct immunologic changes in vivo. J Immunol 194: 950-959.

Furudate S, Fujimura T, Kambayashi Y, Hidaka T, Hashimoto A, Aiba S (2016) Sequential therapy with nivolumab followed by ipilimumab induces complete response in metastatic melanoma of the lung but with severe hepatotoxicities. Case Rep Oncol 9: 644-649.

Imafuku K, Yoshino K, Yamaguchi K, Tsuboi S, Ohara K, Hata H (2017) Comment on 'Efficacy and toxicity of treatment with the anti-CTLA-4 antibody ipilimumab in patients with metastatic melanoma after prior anti-PD-1 therapy'. Br J Cancer, e-pub ahead of print 21 March 2017; doi:10.1038/bjc.2017.58.

Khoja L, Butler MO, Chappell MA, Hogg D, Joshua AM (2015) Increased treatmentrelated toxicity subsequent to an anti-PD-1 agent. Curr Oncol 22(4): 320-322.

Long GV, Robert C, Blank CU, Ribas A, Mortier L, Schachter J, Middleton MR, Neyns B, Sznol M, Zhou H, Ebbinghaus S, Ibrahim N, Arance A (2016) Outcomes in patients with ipilimumab after pembrolizumab in KEYNOTE-006. Society for Melanoma Research Congress, 6-9 November 2016, Boston, MA, USA.

Ribas A, Hamid O, Daud A, Hodi FS, Wolchok JD, Kefford R, Joshua AM, Patnaik A, Hwu WJ, Weber JS, Gangadhar TC, Hersey P, Dronca R, Joseph RW, Zarour H, Chmielowski B, Lawrence DP, Algazi A, Rizvi NA, Hoffner B, Mateus C, Gergich K, Lindia JA, Giannotti M, Li XN, Ebbinghaus S, Kang SP, Robert C (2016) Association of pembrolizumab with tumor response and survival among patients with advanced melanoma. JAMA 315(15): 1600-1609.

Weber JS, D'Angelo SP, Minor D, Hodi FS, Gutzmer R, Neyns B, Hoeller C, Khushalani NI, Miller Jr WH, Lao CD, Linette GP, Thomas L, Lorigan P, Grossmann KF, Hassel JC, Maio M, Sznol M, Ascierto PA, Mohr P, Chmielowski B, Bryce A, Svane IM, Grob JJ, Krackhardt AM, Horak C, Lambert A, Yang AS, Larkin J (2015) Nivolumab versus chemotherapy in patients with advanced melanoma who progressed after anti-CTLA-4 treatment (CheckMate 037): a randomized, controlled, open-label, phase 3 trial. Lancet Oncol 16(4): 375-384.

This work is published under the BJC's standard license to publish agreement. After 12 months the license terms will change to a Creative Commons AttributionNonCommercial-Share Alike 4.0 Unported License. 